\title{
Thematic Issue: New Insights into Current Attachment Research - In Honor of the 80th Birthday of Klaus Grossmann
}

\author{
Lieselotte Ahnert* \\ Department of Developmental Psychology, University of Vienna, Vienna, Austria
}

Germany's best-known attachment researcher, Klaus Grossmann, has come of age. Celebrating his 80th birthday with a two-day symposium and thereby contributing to the festive events during the 650th anniversary of the University of Vienna, Grossmann's scholars, colleagues and friends gathered in the old town hall of Vienna/Austria. Here, they presented him and his wife Karin their current work. This thematic issue presents selected pieces of this research including discussions from colleagues from the audience to reproduce the vivid debate from the symposium.

\section{When Attachment Research Began in Europe}

Without a doubt, Klaus Grossmann has been the one who brought the attachment subjects to Europe, helping the theory to develop and spread out, increasingly accompanied by German as well as Austrian scholars. From the very beginning, however, Klaus made Karin Grossmann join him in this endeavor to establish attachment research in Europe. The Grossmanns started the first mother-child study outside of the US in the mid ' $70 \mathrm{~s}$ in Bielefeld/Germany. To their great surprise, almost half of the sample displayed suboptimal attachment patterns, which was much less than known from the US samples around that time. Strangely, the Bielefeld mothers

\footnotetext{
*Address for correspondence

Prof. Dr. Lieselotte Ahnert, Faculty of Psychology, University of Vienna, Department of Developmental Psychology, Liebiggasse 5, A-1010 Vienna, Austria. Tel.: +43 14277472 60; E-mail: lieselotte.ahnert@univie.ac.at
}

did not behave as dismissively towards their children as the data would suggest, and thus contrasted to the former knowledge on attachment qualities which had linked suboptimal mother-child attachments to maternal insensitivity. As a result, the Bielefeld Study initiated a comprehensive search for the antecedents as well as sequelae of attachment from then on. This thematic issue follows this line of research and confirms that today's attachment research works cross-contextually and cross-culturally in order to place children's attachment experience into the multi-faceted loci of children's care ecology and developmental paths.

\section{How Klaus Grossmann Came Across Attachment}

Klaus Grossmann studied psychology at the Psychological Institute in Hamburg/Germany with Curt Bondy, and was awarded a Fulbright grant with which he continued to study at the University of Arkansas, Las Cruces/New Mexico. Before moving to US, he married Karin Mailandt, who followed him in 1962 after she had finished high school in Hamburg. Karin became his most important research companion, coinvestigator and co-author of all his later research activities.

Back in Germany, Klaus Grossmann was hired by Bernhard Hassenstein for his ethological oriented research at the Zoological Institute in Freiburg/Germany. Klaus appreciated this work very much because it appeared to him as a "Darwinian Contrast Program" to many of the psychological 
approaches that he had been faced with during his past career. With great enthusiasm, he studied the social lives of honey bees in Freiburg, and thus became an unusually precise observer throughout the many experiments he had designed und carried out.

In the late " $60 \mathrm{~s}$, Klaus Grossmann came across the Bowlby-Ainsworth concept on attachment and paid a visit to Mary Ainsworth in 1973. As he had become a full professor at the Educational College of Westfalen-Lippe in 1970, he decided to replicate Ainsworth's Baltimore Study with Karin and his students which lead to the landmark Bielefeld-Study (see above). In 1978, Klaus became a full professor at the University in Regensburg/Germany, where he commenced the next famous Regensburg-Study. Moreover, his lab at the University of Regensburg developed into the "Mecca" of European attachment research, where John Bowlby also received the honorary doctorate. Twenty-three attachment scholars finished their $\mathrm{PhD}$ there; four of them became full professors and many hold higher positions in research institutions, political administrations and clinical practices today. Together with their young scholars and colleagues around the world, Klaus and Karin Grossmann published almost 300 articles and books which belong to the present book inventory of any library in Germany and abroad.

\section{How the Attachment Community Honored Grossmanns' work}

The Grossmanns received the Bowlby-Ainsworth Award of the New York Attachment Consortium in 2006, and in 2007, the Arnold-Lucius-Gesell Award of the Theodor Hellbrügge Foundation, with which they were honored for their unique place in the history of attachment research.

The symposium in Vienna, however, honored the Grossmanns with a performance of a cabaret which originated in 1929 when the Buehler team hosted the Inaugural Congress of the German Society of Psychology in Vienna, and showed scenes of the situation of psychology around that time. For the birthday celebration, this old cabaret was thoroughly revised. Consisting of five images of the old scenes, several topics of the attachment research which have been both carried out and supervised by Klaus Grossmann and his wife, were presented. Thus, the cabaret addressed the evolutionary legacy of the attachment system and the landmark projects of the Grossmanns.
Other issues in the scope of Grossmann's research were also focused on, for example, how attachment can be measured and what attachment really means for child stress regulation. The entire staff of the Developmental Department of the Faculty of Psychology at University of Vienna performed this entertainment in the basement of Café Landtmann, where the "Theater Tribüne", the oldest still existing small stage, is located.

\section{What Issues of Attachment were in the Debate of the Vienna Symposium}

The two-day symposium focused on several key points of the current attachment research, which were organized both traditionally through presentations and discussions, but also in five small "after-meetings" where young scholars in particular were given the opportunity to debate with senior researchers of attachment about topics that the symposium had left open. The traditional presentations were oriented towards mysteries around attachments and their Inner Working Models, the challenges in early development and how they are linked to attachments, and finally, towards disorders in attachment development as well as the power of correcting and repairing them.

The topics that this thematic issue selected from the symposium, however, suggest three focal subjects of how attachment evolves in order to shed better light on attachment formations under specific conditions. Thus, the thematic issue examines attachment patterns (a) in children born preterm to clarify whether and in what respect overall delays in development carries over to early attachment formation, (b) in children cared for by non-maternal providers to explore the factors that facilitate or hinder the building-up processes of attachments in general, and (c) trans-generational processes asking how mothers' own attachment experiences shape the attachment formation of their children.

The thematic issue invited thirteen attachment researchers to provide and discuss these topics which centrally contribute to the pathway concept of attachment development. Despite the fact that the approach to these topics has been rooted in lengthy and tediously demanding observations, the papers are demonstrating the power of ethological observations as well as longitudinal analysis with which the Grossmanns have spent much of the lifetime throughout their impressive careers. 


\section{Bio Sketch}

Lieselotte Ahnert, Professor of Developmental Psychology at University of Vienna, received her PhD from Humboldt-University Berlin (1982) and University at Jena (2000). Her research is concerned with early interaction patterns, and mother-child and father-child attachments throughout the preschool years, social-emotional development in different contexts, i.e. in families and out-of-home care, behavioral adaptation, and stress reactivity. 